\title{
Salivary Oxytocin Concentration Changes during a Group Drumming Intervention for Maltreated School Children
}

\author{
Teruko Yuhi ${ }^{1, *}$ (D) , Hiroaki Kyuta ${ }^{2}$, Hisa-aki Mori ${ }^{2}$, Chihiro Murakami ${ }^{2}$, Kazumi Furuhara ${ }^{1}$, \\ Mari Okuno ${ }^{1}$, Masaki Takahashi ${ }^{2}$, Daikei Fuji ${ }^{2}$ and Haruhiro Higashida ${ }^{1}$ \\ 1 Department of Basic Research on Social Recognition, Research Center for Child Mental Development, \\ Kanazawa University, Kanazawa 920-8640, Japan; furururukz.999@gmail.com (K.F.); \\ brainsci@med.kanazawa-u.ac.jp (M.O.); haruhiro@med.kanazawa-u.ac.jp (H.H.) \\ 2 Lumbini Gakuen Ayabe, A Short-Term Therapeutic Institution for Emotionally Disturbed Children, \\ Social Welfare Juridical Corporation Lumbini-en, Ayabe, Kyoto 629-1244, Japan; \\ kyuuta.hiroaki@rouge.plala.or.jp (H.K.); hkty.08450888@gmail.com (H.M.); \\ muracami814@yahoo.co.jp (C.M.); ize00157@nifty.com (M.T.); daikei.fuji@gmail.com (D.F.) \\ * Correspondence: y-teruko@med.kanazawa-u.ac.jp; Tel.: +81-076-265-2457
}

Received: 25 July 2017; Accepted: 13 November 2017; Published: 16 November 2017

\begin{abstract}
Many emotionally-disturbed children who have been maltreated and are legally separated from their parents or primary caregivers live in group homes and receive compulsory education. Such institutions provide various special intervention programs. Taiko-ensou, a Japanese style of group drumming, is one such program because playing drums in a group may improve children's emotional well-being. However, evidence for its efficacy has not been well established at the biological level. In this study, we measured salivary levels of oxytocin (OT), a neuropeptide associated with social memory and communication, in three conditions (recital, practice, and free sessions) in four classes of school-aged children. Following the sessions, OT concentrations showed changes in various degrees and directions (no change, increases, or decreases). The mean OT concentration changes after each session increased, ranging from $112 \%$ to $165 \%$. Plasma OT concentrations were equally sensitive to drum playing in school-aged boys and girls. However, the difference between practice and free play sessions was only significant among elementary school boys aged 8-12 years. The results suggest that younger boys are most responsive to this type of educational music intervention.
\end{abstract}

Keywords: child abuse; maltreatment; intervention; drum playing; salivary; oxytocin

\section{Introduction}

Childhood maltreatment represents the most potent predictor of poor mental health across the lifespan [1-3]. Such adversity increases the risk of a wide range of psychiatric disorders, including reactive attachment disorder (RAD) and autism spectrum disorder (ASD) [4-7]. Children with ASD and RAD experience similar difficulties with social relationships [8-10], but there appears to be a difference in the quality of their social interactions. In most cases it is possible to differentiate between children with ASD and children with RAD via structured observation. The most important difference is that RAD is associated with neglect or maltreatment, whereas ASD usually is not $[8,9]$.

Children who are found to have been maltreated are entrusted to a foster parent or admitted to a children's home, a short-term therapeutic institution for emotionally disturbed children, or a children's self-reliance support facility [11-13]. In Japan, emotionally-disturbed children, including those who have been maltreated, are either admitted to a short-term therapeutic institution or treated as out-patients, and receive consultation and other assistance. Children who are resident in such institutions learn to adapt to social life while living together in groups, and also receive compulsory education [12,13]. 
It is increasingly recognized that music-making interventions can enhance mental health [14-16]. Among them, drumming has long been a part of traditional healing rituals worldwide, and is increasingly used as a therapeutic strategy [17-19]. The features of group drumming programs are known to facilitate mental health recovery. The findings of previous studies support the concept of "creative practice as mutual recovery", demonstrating that group drumming provides a creative and mutual learning space in which mental health recovery can take place $[17,18,20]$. These reports indicate a shift away from a pro-inflammatory toward an anti-inflammatory immune profile. Consequently, the psychological benefits of group drumming and the underlying biological effects support its therapeutic potential for mental health $[18,20]$. Drumming is a complex composite intervention with the potential to modulate specific neuroendocrine and neuroimmune parameters in the opposite direction to that of the classic stress response [20].

Recent studies have suggested that oxytocin (OT) plays a role in social memory and behavior [21-28]. OT has positive effects on social and emotional processes in healthy subjects and some individuals diagnosed with a variety of psychiatric disorders [29-33]. Nasal application of OT in subjects with ASD with or without comorbid intellectual disability has been shown to improve social interactions [34-38].

This study was conducted in a facility where children with mild emotional disturbance live and study together. Most of them are isolated from their parents and primary caregivers, owing to maltreatment and neglect. The institute offers special educational intervention programs, such as group drumming, to improve their emotional well-being. However, the facility does not use any biological measures to monitor the beneficial effects of group drumming. Salivary OT can be measured in human saliva, suggesting that it may be a reliable biomarker [39-46]. Therefore, we examined whether maltreated school-aged children exhibited changes in OT concentrations during educational sessions based on Japanese Taiko group drumming (Supplementary Figure S1) [47]. In this study, we measured salivary OT concentrations in children before and after recital or practice drumming sessions and compared them with those in free play sessions. We also analyzed changes in OT concentrations by classifying participants by sex and age, such as boys in the elementary school (8-12 years old) and junior high school (13-15 years old), or girls in the elementary school. We also measured OT concentrations in the children's drumming instructors.

\section{Materials and Methods}

\subsection{Participants}

The study recruited 23 boys and five girls aged $8-15$ years as voluntary participants (Table 1 ). The children had lived for between 0.5 and six years in the short-term therapeutic institution for emotionally-disturbed children, run by the Social Welfare Juridical Corporation Lunbini-en (Ayabe, Kyoto, Japan). They attended either the elementary or the junior high school attached to the Lunbini-en. The children were placed in this facility by municipal or prefectural child guidance centers because they were considered to be in need of daily life guidance due to their family environment. We obtained data from three male drumming instructors who taught at the schools ( $36.2 \pm 3$ years old).

Table 1. Demographic data.

\begin{tabular}{cccc}
\hline Standing & Elementary School & Junior High School & Teacher \\
\hline Age (years) & $8-12(9.9 \pm 0.9)$ & $13-15(14.4 \pm 0.4)$ & $33-40(36.2 \pm 3)$ \\
\hline Gender & & & \\
\hline male & 9 & 0 & 3 \\
female & 5 & & \\
\hline Intervention duration (min) & & $118 \pm 16.5(n=6)$ & \\
\hline None & & $108 \pm 10.2(n=5)$ & \\
Practice & $14.1 \pm 3.5(n=12)$ & \\
Recital &
\end{tabular}




\subsection{Ethics Statement}

The study was approved as a non-invasive medical study by the institutional review board of the Social Welfare Juridical Corporation Lunbini-en in 2014 and by Kanazawa University Graduate School of Medicine in 2015 (approval number \#2012-1). The study was performed according to the Declaration of Helsinki and the Ethical Guidelines for Clinical Studies of the Ministry of Health, Labor and Welfare of Japan. After they had been given a complete explanation of the study, all of the participants and their caregivers or the child welfare officers in the child guidance centers provided written informed consent. The participants were told that they could choose not to supply their saliva on each occasion, even after agreeing to participate in the study.

\subsection{Assessment}

The children's salivary OT levels were assessed during 19 sessions of group Taiko drumming (Supplementary Figure S1) from July 2015 to December 2016. The children played freely for the first $10 \mathrm{~min}$. Saliva was collected in a sterile 15-mL polyproprylene tube (Greiner Bio-one Co. Ltd., Tokyo, Japan). Two to five minutes after rinsing with water, the children's mouths filled with newly-secreted saliva. They bit the tube in their mouths and secreted saliva directly into the tube by chewing for 2-4 min. This method was less stressful for such children than using a cotton swab and they were able to complete it by themselves without teachers' assistance. Then they participated in a 5-60 min (14.1 $\pm 3.5 \mathrm{~min}, n=14)$ during recitals on stages in front of an audience (Supplementary Figure S2), or six 80-155 $\min (108 \pm 10.2 \mathrm{~min}, n=6)$ practice sessions in a hall at the Lunbini-en (Supplementary Figure S3, upper panels). Saliva was collected a second time after $10 \mathrm{~min}$ of all sessions. As a control, saliva was collected $10 \mathrm{~min}$ before and after the free play sessions (during which they usually moved, chatted, and read freely) for $90-200 \min (118 \pm 16.5, n=6)$ in the same hall or playground of the Lunbini-en (Supplementary Figure S3, lower panels).

\subsection{Saliva Collection and Analysis}

The saliva samples $(0.3-0.8 \mathrm{~mL})$ were collected in polyproprylene tubes and were immediately frozen in dry ice and stored at $-20^{\circ} \mathrm{C}$, as described previously [48]. Three days later, they were thawed and centrifuged twice at $4{ }^{\circ} \mathrm{C}$ at $1500 \times g$ for $15 \mathrm{~min}$. The samples were divided into 1.5 -mL microtubes, each containing $100 \mu \mathrm{L}$, and kept again at $-80^{\circ} \mathrm{C}$ until assay.

Salivary OT was measured using a 96-plate commercial OT-ELISA kit (Enzo Life Sciences, Farmingdale, NY, USA), as described previously $[48,49]$. Measurements were performed in duplicate. Samples $(100 \mu \mathrm{L})$ without fractionation were treated according to the manufacturer's instructions. The optical density of the samples and standards was measured at wavelengths of 405 and $590 \mathrm{~nm}$ by a microplate reader (Bio-Rad, Richmond, CA, USA). Sample concentrations were calculated by MatLab-7 (MathWorks, Inc., Natick, MA, USA) according to the relevant standard curve.

\subsection{Statistical Analysis}

Two-tailed Student's $t$ tests were used for single comparisons between two groups. One- or two-way analyses of variance were used for data with two or three components, respectively. Post hoc comparisons were performed only when the main effect was statistically significant. The $p$-values of the multiple comparisons were adjusted using Bonferroni's correction. All data from in vivo and in vitro studies are shown as means \pm s.e.m. In all analyses, $p<0.05$ was taken to indicate statistical significance. All of the analyses were performed using STATA data analysis and statistical software (Stata Corp. LP, College Station, TX, USA). 


\section{Results}

Table 1 shows the demographic characteristics of the participants in the traditional Japanese Taiko group. A total of 23 boys and five girls from the elementary and junior high schools were involved in the sessions, during which three male teachers instructed them to play a piece of music.

The OT concentrations in the saliva collected from the children and adults before the performance and control sessions were determined and used as the baseline OT levels (Table 2). The average baseline salivary OT level did not differ significantly between assessments for any of the groups, but the highest value was obtained from the elementary school boys. The OT concentrations in the saliva after different activities (recital, practice (lesson), and free) were plotted separately for the elementary school boys (Figure 1), junior high school boys (Figure 2), elementary school girls (Figure 3), and teachers (Figure 4). No significant differences were observed before and after sessions in the four groups of participants, except for teachers at the recitals $(p<0.01)$.

Table 2. Baseline concentrations of oxytocin $(\mathrm{pg} / \mathrm{mL})$.

\begin{tabular}{|c|c|c|c|c|c|}
\hline & \multicolumn{2}{|c|}{ Boys } & \multirow{2}{*}{$\begin{array}{c}\text { Girls } \\
\text { Elementary School }\end{array}$} & \multirow{2}{*}{$\begin{array}{c}\text { Adults } \\
\text { Teachers }\end{array}$} & \multirow{6}{*}{$\begin{array}{c}F_{3,109}=3.36 \\
(p=0.0215) \\
F_{3,45}=1.61 \\
(p=0.1992) \\
F_{3,173}=6.09 \\
(p=0.0006)\end{array}$} \\
\hline & Elementary School & Junior High School & & & \\
\hline Free activity & $166 \pm 34(32)$ & $259 \pm 23(39)$ & $179 \pm 30(26)$ & $142 \pm 34(14)$ & \\
\hline Practice & $83 \pm 29(14)$ & $176 \pm 48(16)$ & $123 \pm 22(13)$ & $103 \pm 21(8)$ & \\
\hline \multirow[t]{2}{*}{ Recital } & $149 \pm 21(44)$ & $265 \pm 31^{* \#}(63)$ & $186 \pm 20(34)$ & $138 \pm 14$ & \\
\hline & $\begin{array}{l}F_{2,84}=1.01 \\
(p=0.3681)\end{array}$ & $\begin{array}{c}F_{2,122}=1.76 \\
(p=0.1768)\end{array}$ & $\begin{array}{l}F_{2,70}=1.23 \\
(p=0.2989)\end{array}$ & $\begin{array}{l}F_{2,58}=0.01 \\
(p=0.9884)\end{array}$ & \\
\hline
\end{tabular}

One-way ANOVA analysis of each matrics is shown. ${ }^{* \#} p<0.01$ for recital in elementary school boys and teachers (Bonferroni's test).

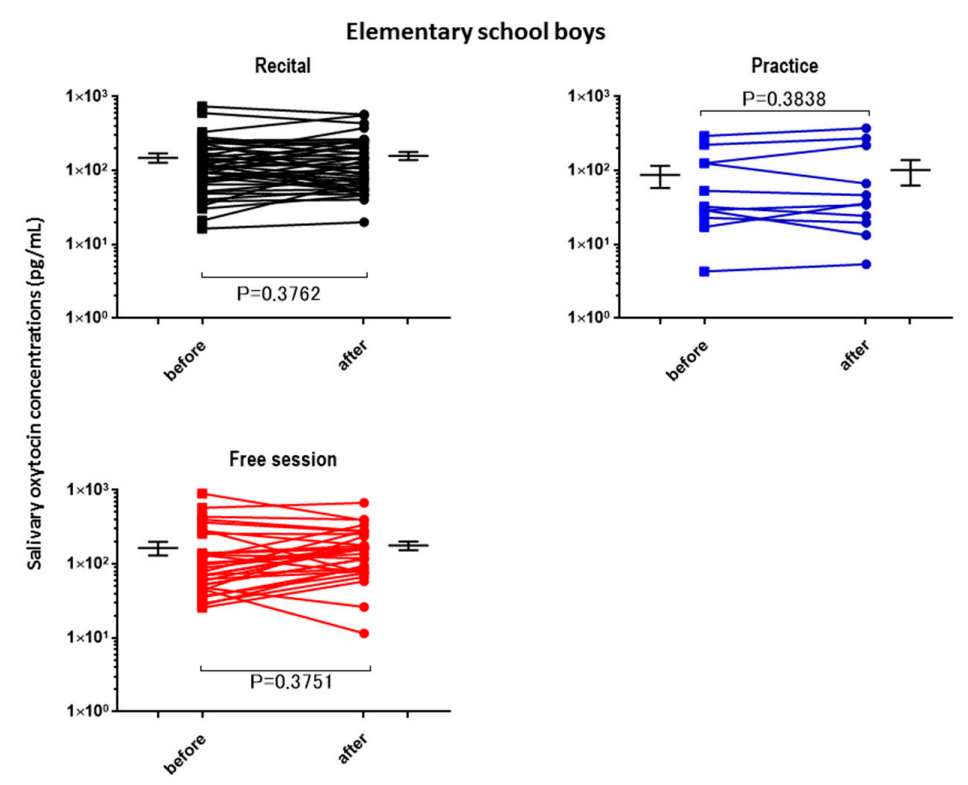

Figure 1. Changes in elementary school boys' oxytocin levels before and after a single play session. Oxytocin levels are for the first (before) and second (after) salivary samples. Saliva was collected at each recital $(n=52)$, practice $(n=11)$, and free play $(n=33)$ session. $p$ values are for two-tailed Student's $t$-tests.

The difference of salivary OT concentrations before and after the activity was calculated. Since the conditions differed in terms of whether an instrument was played and the duration, we compared the changes in OT between non-obligatory activities and practice with the instrument with a similar 
time gap (Figure 5). Similarly, the difference was compared between recital and practice, both of which involved playing the drums (Figure 6). Significant changes in the ratio of salivary OT levels before and after activities and between playing practice and free sessions were observed only in the elementary school boys (two-way Student's $t$-test, $n=11-34, p<0.02$ ).

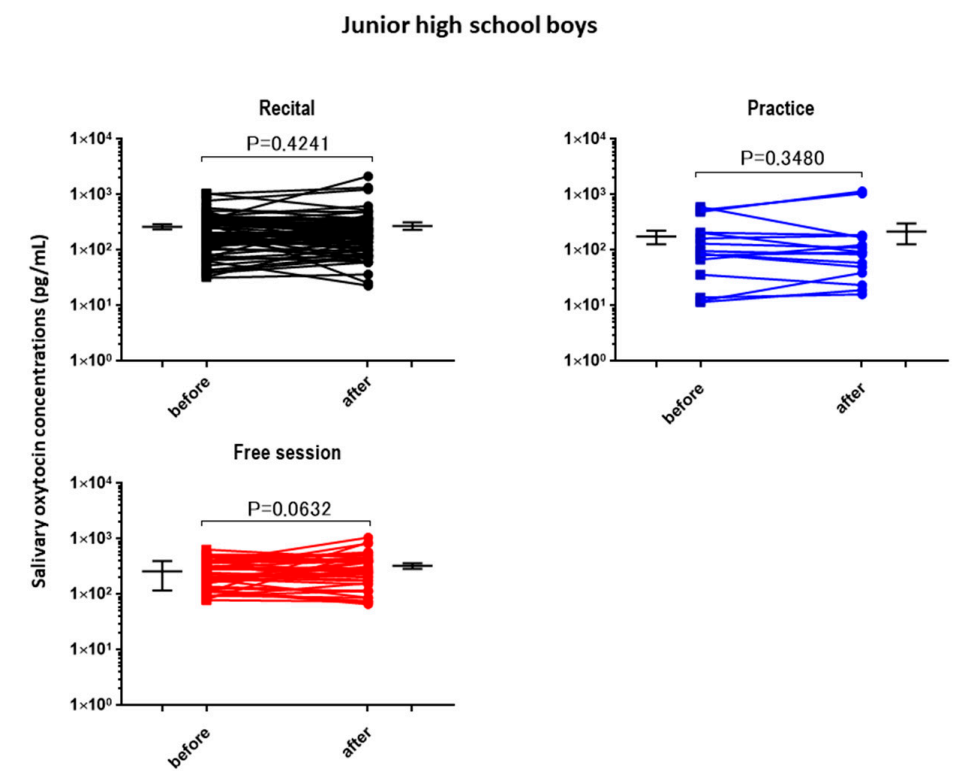

Figure 2. Changes in junior high school boys' oxytocin levels before and after a single play session. Oxytocin levels are for the first (before) and second (after) salivary samples. Saliva was collected at each recital $(n=61)$, practice $(n=17)$, and free play $(n=55)$ session. $p$ values are for two-tailed Student's $t$-tests.

\section{Elementary school girls}

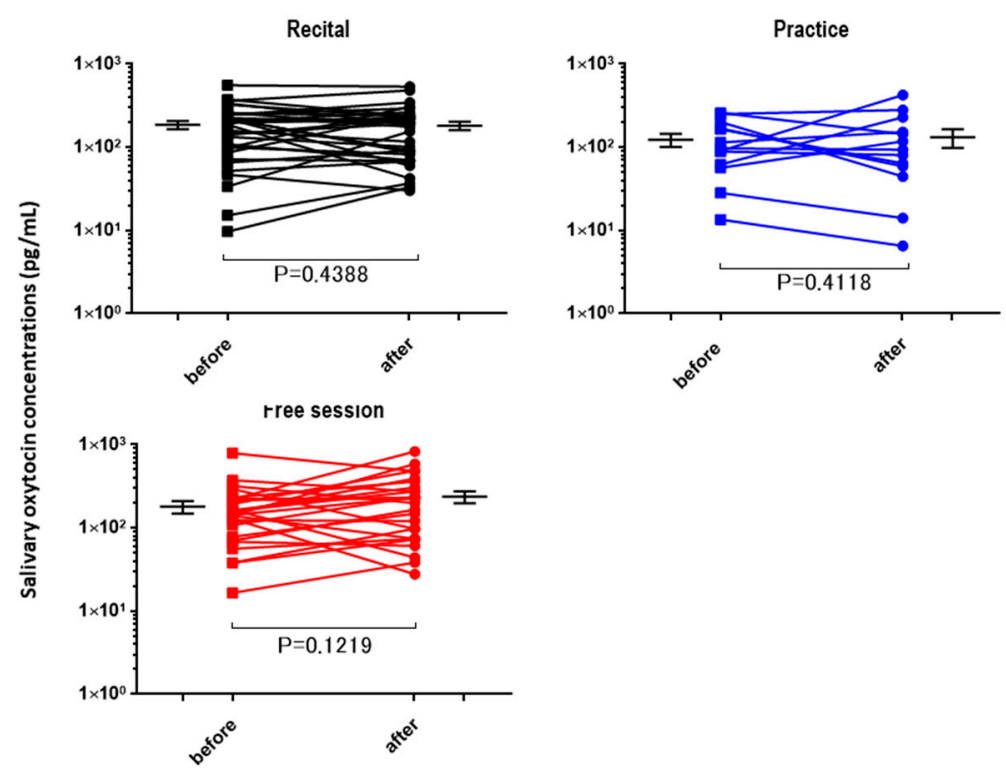

Figure 3. Changes in elementary school girls' oxytocin levels before and after a single play session. Oxytocin levels are for the first (before) and second (after) salivary samples. Saliva was collected at each recital $(n=33)$, practice $(n=14)$, and free play $(n=30)$ session. $p$ values are for two-tailed Student's $t$-tests. A significant difference was found for the recital session. 
Teachers
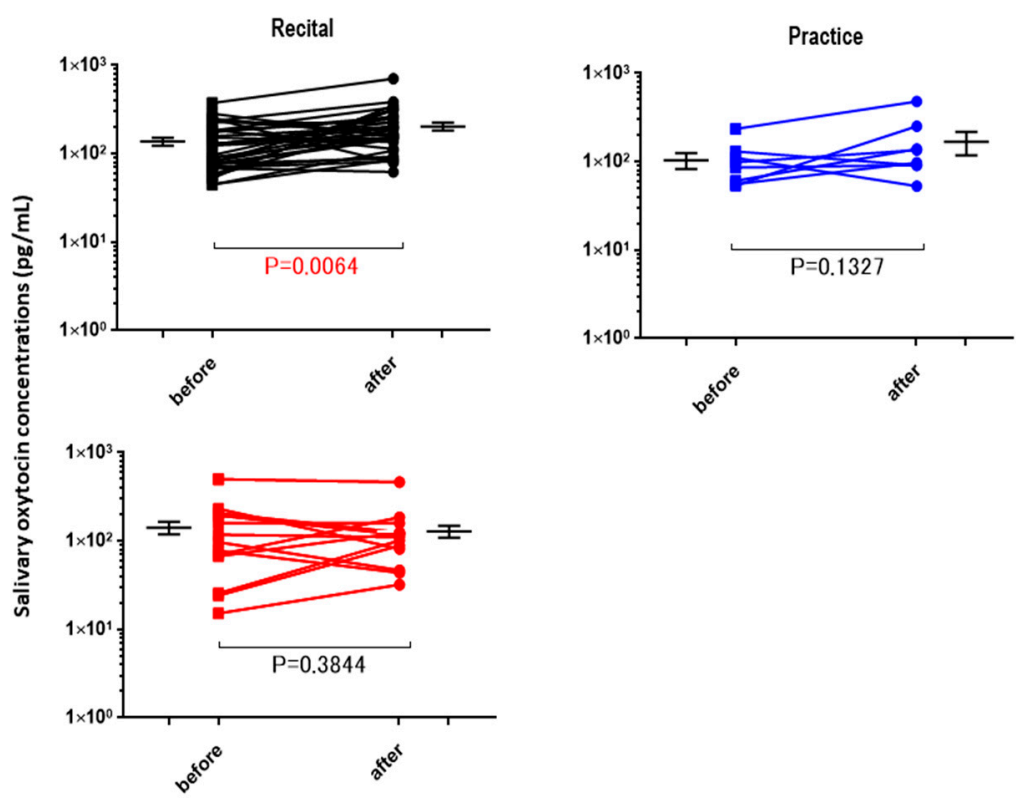

Figure 4. Changes in teachers' oxytocin levels before and after a single play session. Oxytocin levels are for the first (before) and second (after) salivary samples. Saliva was collected at each recital $(n=33)$, practice $(n=8)$, and free play $(n=14)$ session. $p$ values are for two-tailed Student's $t$-tests.
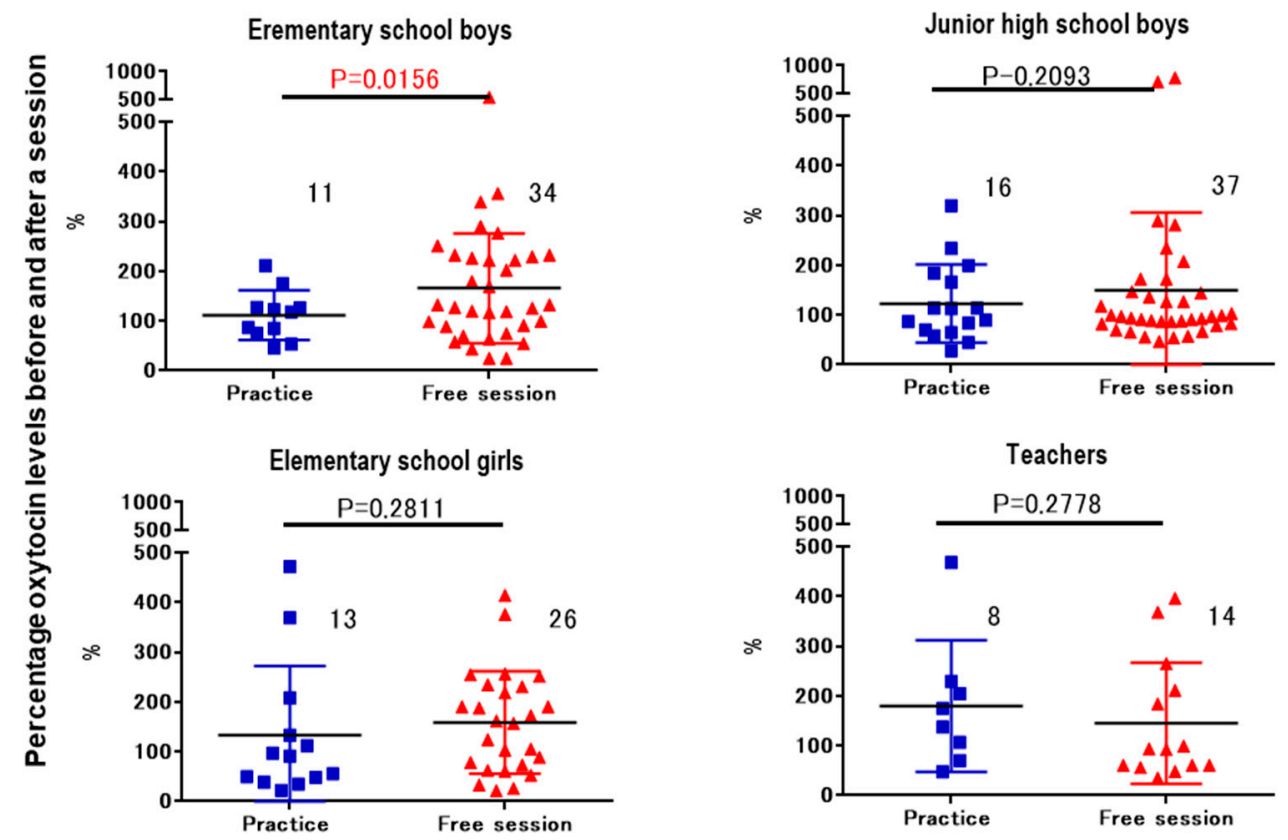

Figure 5. Changes in oxytocin levels before and after a single session. Percentage of oxytocin levels for the first (before) saliva over the second (after) saliva samples. Saliva was collected at practice and free play sessions from elementary school boys, junior high school boys, elementary school girls, and teachers. $p$ values are for two-tailed Student's $t$-tests. 

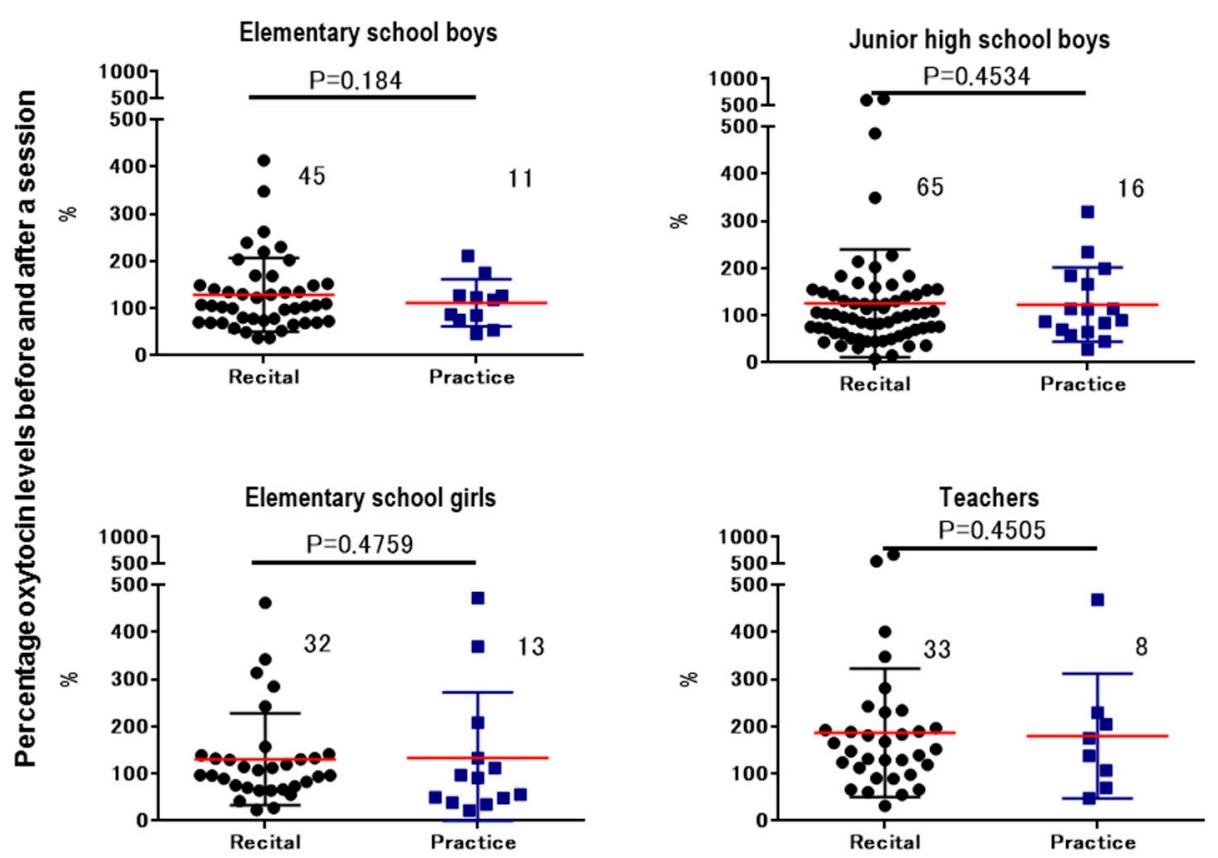

Figure 6. Changes in oxytocin levels before and after a single session. Percentage of oxytocin levels for the first (before) saliva over the second (after) saliva samples. Saliva was collected at recital and practice sessions from elementary school boys, junior high school boys, elementary school girls, and teachers. $p$ values are for two-tailed Student's $t$-tests.

\section{Discussion}

We examined the biological effects of playing music in a Japanese Taiko drumming group. This activity was performed less than once a week as part of an educational intervention for children living and studying in a short-term therapeutic institution for emotionally disturbed children, most of whom were legally separated from their parents or caregivers because of maltreatment $[12,13]$. The results indicated that the children's mean salivary OT concentrations were increased to various degrees after the activity sessions. The smallest increase was observed in the elementary school boys during the practice session and the largest change was in the girls of the elementary school after the free session. However, the only significant difference was between practice and free sessions for boys aged 8-12 years (Figure 5), although a similar tendency was observed in the junior high school boys and elementary school girls, it was not significant. The change in OT concentration was in the reverse direction, i.e., higher during practice than free time, although in the teachers' case it was during drumming instruction.

The reason such significant changes were observed only in younger boys may be that drum playing creates a better atmosphere for younger boys than older ones. In other words, drum playing may not be stressful for older boys but for younger boys because high school boys are already familiar with drumming. Drumming on a stage in front of an audience (recital) and playing for practice (rehearsal) may be essentially different for the players. In addition, the performing time was also different: recitals lasted only $14 \mathrm{~min}$ on average, compared with $108 \mathrm{~min}$ for practice. This makes it difficult to compare the three groups on the different conditions, but as the experiment did not interfere with the institutional routine, optimal ecological validity was maintained.

However, even shorter activities seemed to be stressful. The average OT concentrations were lower after group drumming recital and practice sessions than before. The effects were evident in boys, and seemed to be due to the group drumming rather than playing individually, which created some stress. The OT concentration changes before and after free play, as a control condition, were in the opposite direction. 
In relation to our study, there are several interesting reports on playing music as a group, which describe differences between singing alone (solo) and in a group. Schladt et al. [50] reported that OT increased in the case of solo singing but not in choir. This suggests that, although singing in a group seems to be a joyful experience and one that facilitates bonding [51], it can be rather stressful. Singing lessons for professional or amateur singers are not the same, because professional singers are achievement-oriented, but amateurs sing for self-actualization or self-expression [52]. For the school children in the current study, it is likely that OT increased owing to the release of emotional tension in the recital or practice sessions. In the teachers, OT significantly increased in the recital sessions (Figure 4), probably because they were satisfied by the children's successful performance.

Overall behavior while staying in this therapeutic institution generally improved: the children thought that the Lumbini-en is safe and secure, solved vigilance, and opened their hearts to the surroundings. They became to sleep well, to feel less anxiety, and less likely to panic with a trivial chance. They became to control themselves according to their opponents and situations. They participated in group activities and continued to go to the inside school. They tried to decide their own lives by themselves, grew self-confidence, and finally got to have the hope of going to alive. Such outcomes of individuals were assessed using the school's behavior and study records. Child welfare officers and teachers rated the children's behavior using a questionnaire. In addition, the officers and teachers felt that drumming can be a positive and effective educational intervention to improve children's behavior.

Next, we considered the relationship between OT concentrations and individual's behaviors. Participants were classified according to the initial OT levels and changes in OT levels before and after a single session. The drumming teachers reported that individuals in the group with OT levels in the recital and free sessions that were higher than average are restless, weaker to stimulation, autistic and hyperactive, compared with other individuals (Supplementary Figure S4). In the teacher's records, participants who showed higher rates of change in OT levels before and after recital or free sessions are relatively hyperactive compared with individuals in other classes (Supplementary Figure S5). These results, interestingly, indicate that OT levels modified to a greater extent in a category of hyperactive boys and girls.

It is worth considering the well-known correlation between OT and group cohesion. It is interesting that in boys free play tended to lead to increased OT levels than did practical lessons. This may be due to the cohesiveness effect. To perform in a recital is stressful, particularly for children with disturbed social function, and is likely to reduce vagal activity and cohesiveness. Increases in OT concentrations correspond to increased vagal activity and vice versa, resulting from the brain mechanism as described in prairie voles [53]. In line with this, a study by Harmat and Theorell [54] showed dramatically reduced vagal activity during a concert compared with during a rehearsal, and particularly among those musicians who reported nervousness in recital.

This study had some limitations. Although the measures of salivary OT were taken two years apart, the number of school children involved was small. Opportunity sampling meant that the number of participants was not constant on each occasion.

It has been reported that salivary OT is frequently measured as the biomarker [41,43,55-58], however, though some of the saliva components interact with the labeled OT in the assay mixture [59]. To test this, we first measured samples spiked with 50, 100, 200, and $400 \mathrm{\rho g} / \mathrm{mL}$. Even the very high level was observed with no addition of spiked OT, suggesting an interaction with nonspecific antibody-interacting substances. Even with interacting substances in the samples, the EIA monitored concentrations were proportional to the spiked OT concentrations, suggesting that monitored values are useful for calculating the ratio between values. Therefore, the difference of OT concentrations before and after the sessions shown in Figures 5 and 6 seems to be reliable.

This study did not address behavioral changes in the children at school. Such tests should be performed using a standard questionnaire survey and the children's school records. Teachers in the Institution have the impression that drumming improves the behavior of children living in care. 
In general, they report that the caregiver-teacher-child relationship improves within the first month up to the end of the year.

In conclusion, this study found that maltreated children responded reasonably well and benefitted from a group drumming intervention, as indicated by their increased salivary OT concentrations. The intervention was effective because the children experienced stress, and the stress-relax cycle is linked to the capacity to control emotional reaction.

Supplementary Materials: The following are available online at http:/ / www.mdpi.com/2076-3425/7/11/152/s1; Figure S1: Various types of Wataiko (Japanese percussions) used for music intervention in group, Figure S2: Recitals performed in front of audiences in various stages in wearing with a festival uniform, Figure S3: Upper panels, practice in a hall; lower panels: free sessions, Figure S4: Oxytocin concentrations of individuals before recital and free play sessions, Figure S5: Changes in oxytocin concentrations of individuals before and after recital and free play sessions.

Acknowledgments: This work was supported by the industry-Academia Collaborative R and D Programs (COI) grant-in-aid from the Ministry of Education, Culture, Sports, Science and Technology of Japan. We thank Maki Rooksby for critical reading. We thank Rachel Baron, from Edanz Group (www.edanzediting.com/ac) for editing a draft of this manuscript. Funding: The industry-Academia Collaborative Research and Development Programs (COI) by the Ministry of Education, Culture, Sports, Science and Technology of Japan (MEXT).

Author Contributions: H.H., M.T. and D.F. designed the experiments. H.H. and T.Y. wrote the manuscript. H.K., H.-a.M., C.M., K.F., M.O., M.T. and T.Y. performed the experiments.

Conflicts of Interest: The authors declare no conflict of interest.

\section{References}

1. Teicher, M.H.; Tomoda, A.; Andersen, S.L. Neurobiological consequences of early stress and childhood maltreatment: Are results from human and animal studies comparable? Ann. N. Y. Acad. Sci. 2006, 1071, 313-323. [CrossRef] [PubMed]

2. McCrory, E.J.; Viding, E. The theory of latent vulnerability: Reconceptualizing the link between childhood maltreatment and psychiatric disorder. Dev. Psychopathol. 2015, 27, 493-505. [CrossRef] [PubMed]

3. McCrory, E.J.; Gerin, M.I.; Viding, E. Annual Research Review: Childhood maltreatment, latent vulnerability and the shift to preventative psychiatry-The contribution of functional brain imaging. J. Child Psychol. Psychiatry 2017, 58, 338-357. [CrossRef] [PubMed]

4. Jaffee, S.R. Child maltreatment and risk for psychopathology in childhood and adulthood. Annu. Rev. Clin. Psychol. 2017, 13, 525-551. [CrossRef] [PubMed]

5. Busso, D.S.; McLaughlin, K.A.; Brueck, S.; Peverill, M.; Gold, A.L.; Sheridan, M.A. Child Abuse, Neural Structure, and Adolescent Psychopathology: A Longitudinal Study. J. Am. Acad. Child Adolesc. Psychiatry 2017, 56, 321-328. [CrossRef] [PubMed]

6. Stein, M.B.; Campbell-Sills, L.; Ursano, R.J.; Rosellini, A.J.; Colpe, L.J.; He, F.; Heeringa, S.G.; Nock, M.K.; Sampson, N.A.; Schoenbaum, M.; et al. Childhood Maltreatment and Lifetime Suicidal Behaviors Among New Soldiers in the US Army: Results From the Army Study to Assess Risk and Resilience in Service members (Army STARRS). J. Clin. Psychiatry 2017. [CrossRef] [PubMed]

7. Oshio, T.; Umeda, M. Gender-specific linkages of parents' childhood physical abuse and neglect with children's problem behaviour: Evidence from Japan. BMC Public Health 2016, 14, 403. [CrossRef] [PubMed]

8. Mayes, S.D.; Calhoun, S.L.; Waschbusch, D.A.; Baweja, R. Autism and reactive attachment/disinhibited social engagement disorders: Co-occurrence and differentiation. Clin. Child Psychol. Psychiatry 2016, 22, 620-631. [CrossRef] [PubMed]

9. Davidson, C.; O’Hare, A.; Mactaggart, F.; Green, J.; Young, D.; Gillberg, C.; Minnis, H. Social relationship difficulties in autism and reactive attachment disorder: Improving diagnostic validity through structured assessment. Res. Dev. Disabil. 2015, 40, 63-72. [CrossRef] [PubMed]

10. McLaughlin, K.A.; Greif Green, J.; Gruber, M.J.; Sampson, N.A.; Zaslavsky, A.M.; Kessler, R.C. Childhood adversities and first onset of psychiatric disorders in a national sample of US adolescents. Arch. Gen. Psychiatry 2012, 69, 1151-1160. [CrossRef] [PubMed]

11. Hermenau, K.; Kaltenbach, E.; Mkinga, G.; Hecker, T. Improving care quality and preventing maltreatment in institutional care-A feasibility study with caregivers. Front. Psychol. 2015, 14, 937. [CrossRef] [PubMed] 
12. Matsushige, T.; Tsutsui, T.; Ogata, M. Mutual aid' beyond formal institutions: Integrated home care in Japan. Curr. Sociol. 2012, 60, 538-550. [CrossRef]

13. Tsutsui, T.; Otaga, M.; Higashino, S.; Cottencin, A. Effects of presence in prefectures of short-term therapeutic institutions for emotionally disturbed children on the types of children that have to be taken care of in self-reliance support facilities and foster homes. J. Natl. Inst. Public Health 2013, 62, 204-212.

14. Daykin, N.; de Viggiani, N.; Pilkington, P.; Moriarty, Y. Music making for health, well-being and behaviour change in youth justice settings: A systematic review. Health Promot. Int. 2013, 28, 197-210. [CrossRef] [PubMed]

15. Cevasco, A.M. Effects of the therapist's nonverbal behavior on participation and affect of individuals with Alzheimer's disease during group music therapy sessions. Music Ther. 2010, 47, 282-299. [CrossRef]

16. Altenmüller, E.; Schlaug, G. Apollo's gift: New aspects of neurologic music therapy. Prog. Brain Res. 2015, 217, 237-252. [PubMed]

17. Perkins, R.; Ascenso, S.; Atkins, L.; Fancourt, D.; Williamon, A. Making music for mental health: How group drumming mediates recovery. Psychol. Well Being 2016, 6, 11. [CrossRef] [PubMed]

18. Fancourt, D.; Perkins, R.; Ascenso, S.; Carvalho, L.A.; Steptoe, A.; Williamon, A. Effects of Group Drumming Interventions on Anxiety, Depression, Social Resilience and Inflammatory Immune Response among Mental Health Service Users. PLoS ONE 2016, 11, e0151136. [CrossRef] [PubMed]

19. Ho, P.; Tsao, J.C.; Bloch, L.; Zeltzer, L.K. The impact of group drumming on social-emotional behavior in low-income children. Evid. Based Complement. Altern. Med. 2011, 2011, 250708. [CrossRef] [PubMed]

20. Bittman, B.B.; Berk, L.S.; Felten, D.L.; Westengard, J.; Simonton, O.C.; Pappas, J.; Ninehouser, M. Composite effects of group drumming music therapy on modulation of neuroendocrine-immune parameters in normal subjects. Altern. Ther. Health Med. 2001, 7, 38-47. [PubMed]

21. Kosfeld, M.; Heinrichs, M.; Zak, P.J.; Fischbacher, U.; Fehr, E. Oxytocin increases trust in humans. Nature 2005, 35, 673-676. [CrossRef] [PubMed]

22. Jin, D.; Liu, H.X.; Hirai, H.; Torashima, T.; Nagai, T.; Lopatina, O.; Shnayder, N.A.; Yamada, K.; Noda, M.; Seike, T.; et al. CD38 is critical for social behaviour by regulating oxytocin secretion. Nature 2007, 446, 41-45. [CrossRef] [PubMed]

23. Feldman, R.; Monakhov, M.; Pratt, M.; Ebstein, R.P. Oxytocin Pathway Genes: Evolutionary Ancient System Impacting on Human Affiliation, Sociality, and Psychopathology. Biol. Psychiatry 2016, 79, 174-184. [CrossRef] [PubMed]

24. Insel, T.R. The challenge of translation in social neuroscience: A review of oxytocin, vasopressin, and affiliative behavior. Neuron 2010, 65, 768-779. [CrossRef] [PubMed]

25. Higashida, H.; Yokoyama, S.; Huang, J.J.; Liu, L.; Ma, W.J.; Akther, S.; Higashida, C.; Kikuchi, M.; Minabe, Y.; Munesue, T. Social memory, amnesia, and autism: Brain oxytocin secretion is regulated by NAD+ metabolites and single nucleotide polymorphisms of CD38. Neurochem. Int. 2012, 61, 828-838. [CrossRef] [PubMed]

26. Dulac, C.; O'Connell, L.A.; Wu, Z. Neural control of maternal and paternal behaviors. Science 2014, 345, 765-770. [CrossRef] [PubMed]

27. Neumann, I.D.; Landgraf, R. Balance of brain oxytocin and vasopressin: Implications for anxiety, depression, and social behaviors. Trends Neurosci. 2012, 35, 649-659. [CrossRef] [PubMed]

28. Burkett, J.P.; Andari, E.; Johnson, Z.V.; Curry, D.C.; de Waal, F.B.; Young, L.J. Oxytocin-dependent consolation behavior in rodents. Science 2016, 351, 375-378. [CrossRef] [PubMed]

29. Zhang, R.; Xu, X.J.; Zhang, H.F.; Han, S.P.; Han, J.S. The Role of the Oxytocin/Arginine Vasopressin System in Animal Models of Autism Spectrum Disorder. Adv. Anat. Embryol. Cell Biol. 2017, 224, 135-158. [PubMed]

30. Quintana, D.S.; Dieset, I.; Elvsåshagen, T.; Westlye, L.; Andreassen, O.A. Oxytocin system dysfunction as a common mechanism underlying metabolic syndrome and psychiatric symptoms in schizophrenia and bipolar disorders. Front. Neuroendocrinol. 2017, 45, 1-10. [CrossRef] [PubMed]

31. MacDonald, K.; Feifel, D. Oxytocin's role in anxiety: A critical appraisal. Brain Res. 2014, 1580, 2-56. [CrossRef] [PubMed]

32. Munesue, T.; Yokoyama, S.; Nakamura, K.; Anitha, A.; Yamada, K.; Hayashi, K.; Asaka, T.; Liu, H.X.; Jin, D.; Koizumi, K.; et al. Two genetic variants of CD38 in subjects with autism spectrum disorder and controls. Neurosci. Res. 2010, 67, 181-191. [CrossRef] [PubMed] 
33. Romano, A.; Tempesta, B.; Micioni Di Bonaventura, M.V.; Gaetani, S. From Autism to Eating Disorders and More: The Role of Oxytocin in Neuropsychiatric Disorders. Front. Neurosci. 2016, 9, 497. [CrossRef] [PubMed]

34. Munesue, T.; Nakamura, H.; Kikuchi, M.; Miura, Y.; Takeuch, N.; Anme, T.; Nanba, E.; Adachi, K.; Tsubouchi, K.; Sai, Y.; et al. Oxytocin for Male Subjects with Autism Spectrum Disorder and Comorbid Intellectual Disabilities: A Randomized Pilot Study. Front. Psychiatry 2016, 7, 2. [CrossRef] [PubMed]

35. Kosaka, H.; Okamoto, Y.; Munesue, T.; Yamasue, H.; Inohara, K.; Fujioka, T.; Anme, T.; Orisaka, M.; Ishitobi, M.; Jung, M.; et al. Oxytocin efficacy is modulated by dosage and oxytocin receptor genotype in young adults with high-functioning autism: A 24-week randomized clinical trial. Transl. Psychiatry 2016, 6, e872. [CrossRef] [PubMed]

36. Watanabe, T.; Kuroda, M.; Kuwabara, H.; Aoki, Y.; Iwashiro, N.; Tatsunobu, N.; Takao, H.; Nippashi, Y.; Kawakubo, Y.; Kunimatsu, A.; et al. Clinical and neural effects of six-week administration of oxytocin on core symptoms of autism. Brain 2015, 138, 3400-3412. [CrossRef] [PubMed]

37. Yatawara, C.J.; Einfeld, S.L.; Hickie, I.B.; Davenport, T.A.; Guastella, A.J. The effect of oxytocin nasal spray on social interaction deficits observed in young children with autism: A randomized clinical crossover trial. Mol. Psychiatry 2016, 21, 1225-1231. [CrossRef] [PubMed]

38. Guastella, A.J.; Gray, K.M.; Rinehart, N.J.; Alvares, G.A.; Tonge, B.J.; Hickie, I.B.; Keating, C.M.; Cacciotti-Saija, C.; Einfeld, S.L. The effects of a course of intranasal oxytocin on social behaviors in youth diagnosed with autism spectrum disorders: A randomized controlled trial. J. Child Psychol. Psychiatry 2015, 56, 444-452. [CrossRef] [PubMed]

39. Carter, C.S.; Pournajafi-Nazarloo, H.; Kramer, K.M.; Ziegler, T.E.; White-Traut, R.; Bello, D.; Schwertz, D. Oxytocin: Behavioral associations and potential as a salivary biomarker. Ann. N. Y. Acad. Sci. 2007, 1098, 312-322. [CrossRef] [PubMed]

40. Van Ijzendoorn, M.H.; Bhandari, R.; van der Veen, R.; Grewen, K.M.; Bakermans-Kranenburg, M.J. Elevated salivary levels of oxytocin persist more than $7 \mathrm{~h}$ after intranasal administration. Front. Neurosci. 2012, 6, 174. [CrossRef] [PubMed]

41. Huffmeijer, R.; Alink, L.R.; Tops, M.; Grewen, K.M.; Light, K.C.; Bakermans-Kranenburg, M.J.; Ijzendoorn, M.H. Salivary levels of oxytocin remain elevated for more than two hours after intranasal oxytocin administration. Neuro Endocrinol. Lett. 2012, 33, 21-25. [PubMed]

42. Weisman, O.; Schneiderman, I.; Zagoory-Sharon, O.; Feldman, R. Salivary vasopressin increases following intranasal oxytocin administration. Peptides 2013, 40, 99-103. [CrossRef] [PubMed]

43. Bhandari, R.; Bakermans-Kranenburg, M.J.; van der Veen, R.; Parsons, C.E.; Young, K.S.; Grewen, K.M.; Stein, A.; Kringelbach, M.L.; van IJzendoorn, M.H. Salivary oxytocin mediates the association between emotional maltreatment and responses to emotional infant faces. Physiol. Behav. 2014, 131, 123-128. [CrossRef] [PubMed]

44. Fujisawa, T.X.; Tanaka, S.; Saito, D.N.; Kosaka, H.; Tomoda, A. Visual attention for social information and salivary oxytocin levels in preschool children with autism spectrum disorders: An eye-tracking study. Front. Neurosci. 2014, 8, 295. [CrossRef] [PubMed]

45. Koven, N.S.; Max, L.K. Basal salivary oxytocin level predicts extra- but not intra-personal dimensions of emotional intelligence. Psychoneuroendocrinology 2014, 44, 20-29. [CrossRef] [PubMed]

46. Jong, T.R.; Menon, R.; Bludau, A.; Grund, T.; Biermeier, V.; Klampfl, S.M.; Jurek, B.; Bosch, O.J.; Hellhammer, J.; Neumann, I.D. Salivary oxytocin concentrations in response to running, sexual self-stimulation, breastfeeding and the TSST: The Regensburg Oxytocin Challenge (ROC) study. Psychoneuroendocrinology 2015, 62, 381-388. [CrossRef] [PubMed]

47. Mizuno, E.; Sakuma, H. Wadaiko performance enhances synchronized motion of mentally disabled persons. Percept. Mot. Skills 2013, 116, 187-196. [CrossRef] [PubMed]

48. Tsuji, S.; Yuhi, T.; Furuhara, K.; Ohta, S.; Shimizu, Y.; Higashida, H. Salivary oxytocin concentrations in seven boys with autism spectrum disorder received massage from their mothers: A pilot study. Front. Psychiatry 2015, 21, 58. [CrossRef] [PubMed]

49. MacLean, E.L.; Gesquiere, L.R.; Gee, N.; Levy, K.; Martin, W.L.; Carter, C.S. Validation of salivary oxytocin and vasopressin as biomarkers in domestic dogs. J. Neurosci. Methods 2017, 293, 67-76. [CrossRef] [PubMed] 
50. Schladt, T.M.; Nordmann, G.C.; Emilius, R.; Kudielka, B.M.; de Jong, T.R.; Neumann, I.D. Choir versus Solo Singing: Effects on Mood, and Salivary Oxytocin and Cortisol Concentrations. Front. Hum. Neurosci. 2017, 11, 430. [CrossRef] [PubMed]

51. Kreutz, G. Does singing facilitate social bonding? Music Med. 2014, 6, 51-60.

52. Grape, C.; Sandgren, M.; Hansson, L.-O.; Ericson, M.; Theorell, T. Does singing promote well-being? An empirical study of professional and amateur singers during a singing lesson. Integr. Physiol. Behav. Sci. 2003, 38, 65-74. [CrossRef] [PubMed]

53. Yee, J.R.; Kenkel, W.M.; Frijling, J.L.; Dodhia, S.; Onishi, K.G.; Tovar, S.; Saber, M.J.; Lewis, G.F.; Liu, W.; Porges, S.W.; et al. Oxytocin promotes functional coupling between paraventricular nucleus and both sympathetic and parasympathetic cardioregulatory nuclei. Horm. Behav. 2016, 80, 82-91. [CrossRef] [PubMed]

54. Harmat, L.; Theorell, T. Heart rate variability during singing and flute playing. Music Med. 2010, 2, 10-17. [CrossRef]

55. Javor, A.; Riedl, R.; Kindermann, H.; Brandstätter, W.; Ransmayr, G.; Gabriel, M. Correlation of plasma and salivary oxytocin in healthy young men-Experimental evidence. Neuro Endocrinol. Lett. 2014, 35, 470-473. [PubMed]

56. Kanat, M.; Heinrichs, M.; Domes, G. Oxytocin and the social brain: Neural mechanisms and perspectives in human research. Brain Res. 2014, 1580, 160-171. [CrossRef] [PubMed]

57. Carson, D.S.; Berquist, S.W.; Trujillo, T.H.; Garner, J.P.; Hannah, S.L.; Hyde, S.A.; Sumiyoshi, R.D.; Jackson, L.P.; Moss, J.K.; Strehlow, M.C.; et al. Cerebrospinal fluid and plasma oxytocin concentrations are positively correlated and negatively predict anxiety in children. Mol. Psychiatry 2015, 20, 1085-1090. [CrossRef] [PubMed]

58. Nishizato, M.; Fujisawa, T.X.; Kosaka, H.; Tomoda, A. Developmental changes in social attention and oxytocin levels in infants and children. Sci. Rep. 2017, 7, 2540. [CrossRef] [PubMed]

59. Leng, G.; Sabatier, N. Measuring Oxytocin and Vasopressin: Bioassays, Immunoassays and Random Numbers. J. Neuroendocrinol. 2016, 28. [CrossRef] [PubMed] 